\title{
Special Issues Involving Periprosthetic Infection in Immunodeficiency Patients
}

\author{
Eduard Tornero ${ }^{*}$, Josep Riba and Sebastian Garcia-Ramiro
}

\author{
Department of Orthopaedic and Trauma Surgery, Bone and Joint Infection Unit, Hospital Clinic, University of \\ Barcelona, Barcelona, Spain
}

\begin{abstract}
Chronic systemic illnesses such as diabetes mellitus, chronic kidney disease (CKD), liver cirrhosis, neoplasia, etc. have been clearly associated with high rates of SWI. However, the exact mechanisms underlying these observations are still under investigation.

Chronic kidney disease (CKD) is a growing problem in our society. Many of these patients will require an arthroplasty and it appears that the prosthetic infection risk for these types of patients is much higher than in the normal population. The risk of complications due to infection seems to be lower in patients with kidney transplants than in patients undergoing haemodialysis. Both prophylaxis and treatment of infection in patients with CKD should be carried out with a strict monitoring of potentially nephrotoxic antibiotics.
\end{abstract}

The literature on the prognosis and risk of infection in patients with haematopoietic stem cell transplant is scarce and occasionally contradictory. The optimal time for the surgery should be determined by taking into account the immunological state of the patient and should be avoided, as much as possible, during the first year after the HSCT.

Child's classification system is the most widely used method of stratifying the surgical risk for patients with cirrhosis; the infection appeared to be associated in a statistically significant way with advanced age and a Child B pre-operative classification.

The prevention of prosthetic joint infections in HIV-infected patients should not be significantly different from the prevention for any other patient. Those patients that receive adequate antiretroviral treatment and periodic laboratory control show infection rates and periprosthetic complications that are similar to those for patients not affected by HIV. Therefore, the patient's level of immunodeficiency is the most important prognostic factor for prosthetic infection.

The particular immunological condition of these patients can lead to infections due to particular microorganisms that immunocompetent patients do not have to deal with. Of all possibilities, because of their frequency and difficulty to treat, infections caused by methicillin-resistant $S$. aureus and fungus are highlighted.

Keywords: Prosthetic joint infection, kidney, liver, HIV, elderly.

\section{INTRODUCTION}

Various factors have been associated with a high risk of surgical wound infection (SWI). The most important factors are those which relate to the level of bacterial contamination and the capacity of the patient to eradicate these microorganisms. The level of bacterial contamination basically depends on the type of surgery that is carried out. Traditionally, surgeries have been classified as: clean, cleancontaminated, contaminated and dirty. Quantitatively it has been shown that when the surgical wound is contaminated by $>10^{5}$ microorganisms per gram of tissue there is a significant increase in the risk of SWI [1]. Nevertheless, in clean surgeries (for example, a hip or knee arthroplasty), the bacterial load that is necessary to produce SWI is lower

*Address correspondence to this author at the Department of Orthopaedic and Trauma Surgery, Bone and Joint Infection Unit. Hospital Clinic, University of Barcelona. Barcelona, Spain;

Tel: 00+34+932275400; Fax: 00+34+932279871;

E-mail: etornero@clinic.ub.es $\left(\leq 10^{2} \mathrm{CFU} / \mathrm{mL}\right)$ and depends on: 1$)$ the correct application of protective measures to avoid skin contamination in patients, the surgeons (hand washing, gloves and masks), the environment (laminar air flow and reduction of the number of people in the operating room) and the surgical tools (sterilisation), 2) the length of the operation (van Kasteren CID) and 3) the virulence of the microorganism. On the one hand, even when the bacterial inoculant is low, it is known that the presence of inert material (prosthesis, pins or screws) facilitates the development of SWI. On the other hand, the bacterial load is thwarted by the patient's local or general immune system. Chronic systemic illnesses such as diabetes mellitus, chronic kidney disease (CKD), liver cirrhosis, neoplasia, etc. have been clearly associated with high rates of SWI. However, the exact mechanisms underlying these observations are still under investigation. For example, blood glucose levels [2] subcutaneous oxygen tension [3] or low body temperature [4] during and after surgery have all been implicated as risk factors for SWI. All these factors have been shown "in vitro" to have a detrimental effect on the essential activity of polymorphonuclear leukocytes in eliminating contaminating microorganisms. Notwithstanding, 
in all likelihood there are many other contributing factors associated with SWI such as pain, malnutrition, obesity or age.

The present article describes the most characteristic situations and evolution of patients with kidney failure, haematopoietic stem cell transplants, liver cirrhosis or HIV infection and elderly patients. Furthermore, special attention is paid to infections that are found almost exclusively in these types of patients such as fungal or MRSA infections.

\section{CHRONIC KIDNEY DISEASE: HAEMODIALYSIS AND KIDNEY TRANSPLANT}

Chronic kidney disease (CKD) is a growing problem in our society [5]. Patients with this disease are initially treated with pharmaceuticals but, over time many ultimately require haemodialysis or kidney transplant. Patients with CKD can develop a degenerative joint disease for various reasons including steroid-induced osteoarthritis or osteonecrosis. Many of these patients will require an arthroplasty for one of these reasons or following a femoral neck fracture [6-8].

The prevalence and treatment of a prosthetic infection in patients with CKD will inevitably vary according to the age of the patient and the evolution of their disease. Many studies have tried to evaluate the inherent complications related to arthroplasty implants in patients undergoing haemodialysis treatment or patients with kidney transplants, as well as the differences between each of these groups. Often these populations have both local and systemic complications that compromise the clinical and functional results of an arthroplasty, and results are traditionally unsatisfactory in comparison to the general population [917].

The main reason for the negative results among this group is the elevated risk of prosthetic loosening due to the low quality and quantity of periprosthetic bone. Furthermore, the risk of periprosthetic infection in these types of patients is also increased.

Patients in long-term treatment with haemodialysis are often immunosuppressed, leading to a higher risk of infection. Liebman et al. reported a $19 \%$ infection rate in these types of patients [11]. Later, Naito et al. also reported an infection rate greater than $12 \%$ [13]. In other more recent studies, Nagoya et al. did not report any infections in a series of 19 Total Hip Athroplasty (THA) patients [12] and in 2009 Fukunshi et al. described a $6 \%$ infection rate in 19 THA patients. In a retrospective study carried out in our hospital on 23 THA patients who received surgery between 1992 and 2005 , we identified a $17 \%$ rate of deep infection [18]. Based on our experience and the published scientific material, it appears that the prosthetic infection risk for these types of patients is much higher than in the normal population.

The risk of complications due to infection seems to be lower in patients with kidney transplants than in patients undergoing haemodialysis [9-21]. Nonetheless, the studies that have been published comparing both groups are few and the results should be evaluated cautiously. In a study published in 2006 by Schrader et al. that compared 9 THA patients undergoing haemodialysis and 36 THA transplant patients, the prosthetic infection rate was found to be $22 \%$ in the former group and $13 \%$ in the latter.

\section{ANTIBIOTICS ELIMINATED BY THE KIDNEY}

Both prophylaxis and treatment of infection in patients with CKD should be carried out with a strict monitoring of potentially nephrotoxic antibiotics. In the large majority of cases, doses should be adjusted according to the patient's Creatinine clearance.

Cefuroxime, which we commonly use at our hospital for prophylaxis of prosthetic infection in primary prosthesis may serve as an example. Patients with CKD should have this prophylaxis modified according to the patient's Creatinine clearance (CLcr):

If CLcr $<10 \mathrm{ml} / \mathrm{min}: 750 \mathrm{mg}$ Cefuroxime upon anaesthetic induction.

If CLcr 10-20 ml/min: $750 \mathrm{mg}$ Cefuroxime at induction and $750 \mathrm{mg} 8$ hours later.

If $\mathrm{CLcr}>20 \mathrm{ml} / \mathrm{min}: 1.5 \mathrm{gr}$ Cefuroxime upon anaesthetic induction.

In fact, a large quantity of antibiotics that are eliminated through the kidneys require strict monitoring in patients with kidney failure.

\section{HAEMATOPOIETIC STEM CELL TRANSPLANTS}

In the past 30 years the number of haematopoietic stem cell transplants (HSCT) has increased considerably. Given that HSCTs are being carried out in increasingly earlier phases of haematological disease, along with the fact that many of the patients are young, the number of patients who survive HSCT is greater and, as a result, more patients are at risk of suffering delayed complications from the disease and adverse effects of treatment. The use of glucocorticoids in the treatment of both the underlying disease and GraftVersus-Host Disease (GVHD) has been identified as one of the main osteonecrosis risk factors in these patients, which is, in turn, the primary indication for arthroplasty in this population.

It should be kept in mind that the patient who receives HSCT is in an immunosuppressed state that persists throughout the first year. Afterwards, however, the immune system's condition depends on the drugs the patient receives, the requirement for splenectomy or the appearance of GVHD.

The literature on the prognosis and risk of infection in these types of patients is scarce and occasionally contradictory. In a series of 27 THA patients with HSCT, Bezet et al. reported a $7.5 \%$ prosthetic infection rate [22]. In a retrospective study carried out at our hospital on 12 THA patients operated on between 1991 and 2002 who had been diagnosed with ischemic necrosis of the femoral head (INFH) in the context of an HSCT, no superficial or deep tissue infections were detected despite the fact that the patients under study had a theoretically greater predisposition to infection [23].

Similarly to the rest of the conditions considered, the immunological state of the patient is a prognostic factor for the risk of prosthetic infection. Sterilisation measures and antibiotic prophylaxis should therefore be intensified. It would be prudent, given the high risk of concomitant infections, to ensure prior to surgery that no concomitant 
septic focal points exist (dental, urinary or cutaneous, among others). Likewise, the optimal time for the surgery should be determined by taking into account the immunological state of the patient and should be avoided, as much as possible, during the first year after the HSCT.

\section{LIVER FAILURE AND CIRRHOSIS}

With the increase in the prevalence of liver diseases and improvements on their treatment and management, orthopaedic surgeons are increasingly faced with the need to intervene on patients with liver cirrhosis [24, 25]. These patients present a greater risk for post-operative complications such as increased bleeding, encephalopathy, kidney failure, multiple organ failure, and, of course, infection [26, 27], thereby considerably increasing postoperative morbidity and mortality [26, 28-30].

Child's classification system is the most widely used method of stratifying the surgical risk for patients with cirrhosis [27-29, 31]:

CHILD-A: Bilirubin $<1.5 \mathrm{mg} / \mathrm{dL}$, albumin $>3.5 \mathrm{~g} / \mathrm{dL}$, prothrombin time $<4$ seconds, no sign of encephalopathy or ascites.

Elective surgery is well tolerated.

CHILD-B: Bilirubin between $1.5-3 \mathrm{mg} / \mathrm{dL}$, albumin between 2.8-3.5 mg/dL, prothrombin time 4-6 seconds or presence of mild ascites or moderate encephalopathy.

Surgery can be performed with pre-operative measures.

CHILD-C: Bilirubin $>3 \mathrm{mg} / \mathrm{dL}$, albumin $<2.8 \mathrm{~g} / \mathrm{dL}$, prothrombin time $>6$ seconds or signs of moderate ascites or serious encephalopathy.

Surgery is contraindicated.

Infection, either systemic or periprosthetic, is the most common complication of joint arthroplasty in these patients [32]. Bacterial infection is, in fact, a common and serious complication in patients with cirrhosis. Prior infections, highly invasive surgical procedures or gastrointestinal bleeding are known risk factors for systemic infection in these patients [33-35].

This predisposition to infection is probably related to the actual failure of the liver and reticuloendothelial cell system [36]. Neutrophil deficit and reduction of phagocytic capacity of macrophages have also been suggested as important contributing factors to this predisposition towards bacterial infection [37, 38]. In a retrospective case-control study carried out by Lih-Yuann Shih et al. in 2004 that included 60 total knee arthroplasties in patients with cirrhosis and 60 control arthroplasties, a periprosthetic infection rate of $8.3 \%$ was found in patients suffering from liver disease. Staphylococcus aureus was the microorganism most frequently isolated and the infection appeared to be associated in a statistically significant way with advanced age and a Child B pre-operative classification. Other risk factors found were the presence of prior liver decompensation in the patient's history or coinfection with hepatitis B.

We believe that it is in these patients that preventative measures should be heightened against infection and that strict post-operative control should be followed in order to proceed aggressively if infection is suspected.

On a different note, patients with liver disease often present simultaneously multiple types of bleeding disorders that increase the risk of intraoperative and post-operative bleeding [39]. Intraoperative blood loss and the posterior need for concentrated red blood cell transfusions reduce the immunological condition of the patients even further. In addition, the formation of a haematoma around the surgical wound in the days following the intervention is yet another risk factor for developing a prosthetic infection. The possible coagulopathies of these patients should be corrected prior to surgery according to established procedures [40] such as vitamin $\mathrm{K}$ administration or concentrated plasma transfusions. In the same study published by Lih-Yuann Shih et al., despite keeping this preventative method in mind, statistically significant differences were found between both groups with respect to intraoperative blood loss. According to the authors, this could partly explain the different infection rates.

\section{HIV INFECTION}

Due to their potentially immunosuppressed condition and propensity to suffer osteonecrosis, patients with chronic HIV infection merit special attention.

Since 1990 [41] numerous studies have related HIV infections with a greater risk for osteonecrosis. Some of the more recent articles have asserted that HIV patients have a 100 times greater risk of developing osteonecrosis and a $4.1 \%$ prevalence of asymptomatic ischemic necrosis of the femoral head (INFH) [42, 43]. Regarding the cause for this increased risk, a lot of controversy exists over the contributing role of combined antiretroviral treatment. A multicentric study carried out in France that reviewed 56,393 patients and was published in 2006 by Murielle Mary-Krause et al., reached the conclusion that both the infection itself as well as the combined antiretroviral treatment were independent risk factors for developing ischemic necrosis of the femoral head [44].

Evolved joint osteonecrosis is a condition with clear indications for an arthroplastic implant. Sadly, however, individuals infected with HIV are traditionally considered bad candidates for surgery due to poor prognosis and the risks of disease progression or disease transmission to healthcare personnel.

The initial case series of hip arthroplasties in HIV positive patients that were published in the beginning of the $21^{\text {st }}$ century reflected a higher infection rate and posterior prosthesis complication rate than for the rest of the population. Javad Parvizi et al. published a series in 2003 of 21 HIV patients who were operated on between 1979 and 1998 for total hip replacements assuring that, after 10 years of follow-up all patients were dead, having required 13 reinterventions and presented 6 deep tissue infections [45]. Another similar study carried out by Christopher Lehman et al. on $29 \mathrm{HIV}+$ patients operated on between 1983 and 1995 reflected, in addition, that the poor prognosis was accentuated even further in patients with a history of intravenous drug use (IDU) [46]). 
More recent studies, nevertheless, have revealed much lower infection rates among this group of patients [47-52]. In 2005, Carig R Mahoney et al. published their results on a group of $40 \mathrm{HIV}$ patients. It agreed with the other articles in the claim that these patients present a significantly higher risk of INFH, but also asserted that post-surgical acute infection rates were much lower than expected [47]. In 2008, Bjoern Haberman et al. published a series of 55 cases of THA on HIV+ patients claiming that the post-operative complications mainly appeared in patients with difficult social circumstances [48]. Also in 2008, Baheback et al. carried out a prospective study at the hospital in Yaoundé, Cameroon on HIV+ patients undergoing any kind of surgical intervention and found that, with prolonged prophylactic antibiotic treatment, the HIV-immunosuppressed patients had the same post-operative infection rates as non-HIV patients [49].

The recommendation since 1997 to use 3 or more antiretroviral agents in the treatment of HIV infections has drastically improved the survival and morbidity of these patients and, we believe, further explains the differences between the results obtained in the studies conducted over the past few years in comparison to the earlier ones.

In a recent comparative study carried out at our hospital, THA on patients with surgical indications resulting from INFH obtained positive results in well-controlled HIV patients. In fact the results were superimposable to non-HIV patients [53].

The prevention of prosthetic joint infections in total hip or knee arthroplasties in HIV patients should not be significantly different from the prevention for any other patient, even if it is important to emphasise some aspects.

As previously mentioned, hip arthroplasty failure or infection in a chronic HIV patient seems to be intimately connected to control of the underlying disease itself and the patient's immunological condition. Those patients that receive adequate antiretroviral treatment and periodic laboratory control show infection rates and periprosthetic complications that are similar to those for patients not affected by HIV. Therefore, the patient's level of immunodeficiency is the most important prognostic factor for prosthetic infection.

Beyond the normal preventative measures carried out on any other patients, patients affected by chronic HIV infection who undergo a hip or knee arthroplasty should receive the following tests taken in the days prior to the intervention:

\section{- $\quad$ CD4 T-lymphocyte count}

- $\quad$ PCR viral load

We believe that elective surgery would be contraindicated in those patients with a CD4 T-lymphocyte count below $\mathbf{4 0 0} \mathrm{cel} / \mathrm{uL}$ (or $<\mathbf{2 0 \%}$ ) or with a PCR viral load over 50 copies $/ \mathrm{ml}$.

\section{ELDERLY PATIENTS}

Hip fractures in elderly patients are a common emergency in every traumatology service in the developed countries. Our hospital, which is located in the centre of Barcelona and serves a population of 400,000 , admits around 400 cases per year with an average age of 80 years. In these cases the elective treatment is surgical synthesis with different materials depending on the type of fracture (subcapital or pertrochanteric). Surgery is an aggressive procedure for a patient and, in the majority of cases, is accompanied by general health and nutritional deterioration prior to the fracture. Studies that were carried out in countries that can be considered socially developed showed that $20 \%$ of the patients who were treated for a hip fracture presented below normal albumin levels at the time they were admitted to the hospital. This situation can worsen following the intervention since all surgical procedures provoke a cytokine-mediated inflammatory response (i.e. IL-1, IL-6) that stimulates acute phase reactants (i.e. fibrinogen) that are meant to assist in healing the wound but at the same time reduce albumin synthesis. Furthermore, the inflammatory response is accompanied by an anti-inflammatory physiological response that is characterised by an increase in cortisol serum levels and a transitory immunosuppression that can favour the development of post-operative infections.

Along with malnutrition and transitory post-operative immunosuppression, other factors exist in elderly patients that frequently favour the development of post-operative infections including: 1) general diseases that are associated with a higher risk of infection (i.e. diabetes mellitus), 2) the need to maintain certain devices in place for prolonged periods of time (i.e. urinary or venous catheter) and 3) altered levels of consciousness, swallowing and coughing reflexes that favour pulmonary microaspirations.

Overall, it is estimated that 5 to 15 patients per 100 admitted to the hospital ultimately suffer a nosocomial infection. On the whole these infections are responsible for a significant increase in hospitalisation time, patient mortality and health care costs. One of the most complicated elements in dealing with nosocomial infections is that they are more often produced by resistant microorganisms.

The two most important factors associated with infection by a resistant microorganism are: 1) presence of other cases of resistant microorganism infections in the hospital unit and 2) 3 or more days of antibiotic treatment by the patient. In the first situation it is clear that microorganisms are transmitted within a care unit fundamentally from the hands of the healthcare personnel. For this reason, any patient who is a carrier or is infected by a resistant microorganism must be isolated. In addition, handwashing with alcoholic solutions by healthcare personnel after contact with patients must be promoted, independently of whether a patient is known to be a carrier of a resistant microorganism or not. To this end, an effective method for dealing with this is the installation of dispensers in all hospital rooms.

Secondly, when antibiotics are administered, the concentration achieved on skin or mucus membranes is much less than what is achieved in plasma. Despite this, in general it is enough to eliminate the (predominant) sensitive bacteria population but not the (minority) resistant population. This determines an "ecological void" that favours, on the one hand, the nesting of resistant microorganisms coming from other patients and also the growth of the resistant population, which can then become predominant. These phenomena become more intense as the antibiotic spectrum becomes wider and length of treatment longer. Because of all of this, once the culture results are 
known it is important to adjust the antibiotic treatment by giving preference to those that carry out a more selective activity against the isolated pathogen and not to prolong the length of treatment unnecessarily.

Prosthetic infection in elderly patients not only increases hospital stays but also lowers functional capacity at 4 months after the fracture and mortality increases during the first year.

Conventional prophylaxis for prosthetic surgery usually consists in administering a first or second generation cephalosporin. Nevertheless, the characteristics of elderly patients admitted to the hospital for a hip fracture are different and the probability that they carry resistant flora is much higher. For this reason, the authors of this article recommend administering a glycopeptide along with a cephalosporin to maintain an adequate level of coverage [54].

The treatment of a superficial infection in an elderly patient's wound can be dealt with orally. In those cases where microbiological information from an exuded sample is available, the treatment can be adapted to the results on the antibiogram. In the absence of aetiological information the antibiotic treatment should be effective against $S$. aureus (amoxicillin-clavulanic or fluoroquinolones, in case of allergy, are recommended). If MRSA infection is suspected the alternative treatment would be Linezolid or Cotrimoxazole.

Antibiotic treatment of deep tissue infections should be initiated after taking deep tissue samples during surgical debridement, except in those cases where the patient has a fever greater than $38^{\circ} \mathrm{C}$, signs of serious sepsis or septic shock. Empirical treatment should cover against the most frequent microorganisms according to the each medical centre's statistics. Nevertheless, in elderly patients the prevalence of infections due to methicillin-resistant Staphylococcus aureus, enterococci and Pseudomonas aeruignosa is very high, for which reason it is recommended that glycopeptide (teicoplanin) or linezolid along with an antipseudomonal active beta-lactam (ceftazidime, cefepime or carbapenem) be used. Once the microorganism causing the infection has been identified, the antibiotic treatment should be adapted to the antibiogram results.

In any case, if the clinical situation of the patient allows it and the evolution of the wound is favourable, the intravenous treatment should last no more than 7 to 10 days. In addition, it is important to monitor the clinical progress, inflammatory response parameters and the appearance of adverse effects, as these are highly frequent situations for these types of patients.

\section{INFECTIONS CHARACTERISTIC OF IMMUNO- DEPRESSED PATIENTS}

The particular immunological condition of these patients can lead to infections due to particular microorganisms that immunocompetent patients do not have to deal with. Of all possibilities, because of their frequency and difficulty to treat, infections caused by methicillin-resistant $S$. aureus and fungus are highlighted.

\section{Methicillin-Resistant Staphylococcus aureus Infection}

In the past 15 years the prevalence of infections caused by methicillin-resistant Staphylococcus aureus (MRSA) in orthopaedic surgery has increased [55]. Hoping to reduce MRSA infections, different authors have evaluated the prophylactic effectiveness of glycopeptides. Mini E et al. [56] reviewed the experiences that compared teicoplanin with cephalosporins in orthopaedic surgery, and demonstrated that both treatments were equally effective. Nevertheless, the prevalence of MRSA in the populations that were studied was low. In a later study on a population with a high prevalence of MRSA, administration of $600 \mathrm{mg}$ of teicoplanin during anaesthetic induction significantly reduced MRSA infection rate [54].

In orthopaedic surgery, $S$. aureus is the most frequent pathogen. $S$. aureus colonises the nasal passages and different studies stated an approximate prevalence of $30 \%$ of the general population. Being an S. aureus carrier is a wellknown risk factor in the development of infections in surgical patients (general surgery, orthopaedics and chest surgery). Kalmeijer et al. [57] explained that patients who were nasal passage carriers of $S$. aureus who underwent orthopaedic surgery, had a significantly higher risk of SWI due to $S$. aureus in comparison to patients who were not $S$. aureus carriers. These findings suggest that nasal passage decolonisation prior to surgery could reduce the incidences of infection due to $S$. aureus. Kalmeijer et al. [58] randomised 614 patients who received mupirocin or a placebo the day before surgery. The molecular characteristics of the $S$. aureus strain in nasal passage mucus and the surgical wound infections showed that endogenous $S$. aureus infections (nasal passage and surgical wound strains were identical) were 5 times more likely in the mupirocin group than in the placebo group, although the difference was not significant (RR 0.19, IC 95\% 0.02-1.62, p $>0.05)$. In another clinical study in general surgery [59] that was designed in a similar way (randomised and double blind), the authors observed a significant reduction of nosocomial infections caused by $S$. aureus. Nevertheless, the SWI rate was similar in the mupirocin and placebo groups, probably because of the unexpectedly low number of SWI caused by $S$. aureus in both groups. In a recent randomised study using mupirocin ointment along with chlorhexidine soap, a significant reduction in superficial and deep infection of the surgical wound in nasal passage carriers of $S$. aureus was demonstrated in comparison to a placebo group [60]. In conclusion, the available information shows that a nasal passage colonisation with $S$. aureus is an important risk factor in the development of SWI due to this microorganism, and that decolonisation of selected patients is likely to be an effective preventative measure.

\section{Fungal Infection}

Fungal infection in a joint prosthesis is a very infrequent occurrence that is mainly caused by Candida spp, although infections produced by $C$. glabrata, $C$. parapsilosis, $C$. tropicalis, Rhodotorula minuta or Aspergillus spp have been found in other published studies [61-73].

A series that was recently published at our medical centre [74] the most important risk factor (present in 9 out of 10 
cases) was prior treatment with one or more antibiotics over a prolonged period (>15 days) as a consequence of a previous infection. The antibiotic treatment destroys the normal patient flora and creates an ecological void that allows an overgrowth of candida on the skin and mucus. In these cases the reintervention (risk factor present in 7 of our patients) can lead to the contamination of the surgical wound from Candida spp which later develops into an infection. The poor prognosis for these types of infections may justify, in high risk patients, a study for colonisation by Candida spp and later the administration of antifungal prophylaxis.

Another possibility is that candida may have been present in the prior infection, having gone unidentified. According to the data from our medical centre, $70 \%$ of patients with a prosthetic infection due to candida had a prior polymicrobial infection with isolated candida, which is a higher number than should be expected in these types of infections [75]. The data suggests that, when presented with a polymicrobial infection, if the patient does not respond well despite being administered adequate antibiotic coverage, a fungal aetiology should be suspected.

Other authors have highlighted patient comorbidity as a risk factor (diabetes mellitus, rheumatoid arthritis and steroid treatment).

Very little literature exists on the treatment for fungal infections and this continues to be a controversial point to this day. In addition, the results obtained are very different from other types of infections. In our own cohort, a twostage revision was carried out in 7 cases (using an antifungal cement spacer) and in 3 cases a debridement was performed without removing the implant. In all of the cases the antifungal treatment was initiated with fluconazole, while two received a combined treatment with echinocandin. Despite all this, all the patients were failures and in 9 of the cases an additional intervention was carried out which consisted in resection arthroplasty in 8 of the cases and resulted in significant functional deterioration for the patients. In the last visit, only 2 patients remained asymptomatic without the need for antifungal treatment. These results are very different from those obtained with infections that were caused by other microorganisms.

Phelan et al. [9] reviewed 10 cases, 4 of their own and 6 from other studies. The difference between our series and the Phelan et al. series was that the two-stage revision in our series had a $29 \%$ success rate (2 out of 7) and Phelan et al. had an $80 \%$ success rate (8 out of 10) [63]. One of the differences is that 6 out of the 8 patients that were cured in the Phelan series were administered amphotericin $\mathrm{B}$, while the patients in our series were treated with fluconazole, which in 2 cases was combined with echinocandin.

Amphotericin B [76] and the new echinocandins [77] are fungicides and act against candida biofilms, whereas fluconazole is a fungistatic and therefore has a reduced effect on biofilms. This difference makes it important to consider the use of new antifungal medications in the future and perhaps, preferably, in combination [78], at least during the first 2 to 4 weeks of treatment.

Given that fungal infection appears to be associated with previous polymicrobial infection due to prior prolonged antibiotic treatment and multiple reinterventions, in those patients that have these characteristics and evolved favourably, a fungal infection could be suspected. The review of the data and our results suggest that it is necessary to use a liposomal formula that consists of amphotericin B, in combination or not with a second antifungal agent. Lastly, the results suggest the need to carry out antifungal prophylaxis on high risk patients undergoing an arthroplasty or surgical revision.

\section{CONFLICT OF INTEREST}

The authors confirm that this article content has no conflict of interest.

\section{ACKNOWLEDGEMENTS}

Declared none.

\section{REFERENCES}

[1] Kizkek TJ, Robson MC. Evolution of quantitative bacteriology in wpund management. Am J Surg 1975;130: 579-84.

[2] Latham R, Lancaster AD, Covington JF, Pirolo JS, Thomas CS Jr. The association of diabetes and glucose control with surgical-site infections among cardiothoracic surgery patients. Infect Control Epidemiol 2001; 22: 607-12.

[3] Greif R, Akça O, Horn EP, Kurz A, Sessler DI; Outcomes Research Group. Supplemental perioperative oxygen to reduce the incidence of surgical-wound infections. N Engl J Med 2000; 324 : 161-7

[4] Kurz A, Sessler DI, Lenhard R. Perioperative normothermia to reduce the incidence of surgical-wound infection and shorten hospitalitation. Study of wound infection and temperature group. N Eng J Med 1996; 334; 1209-15.

[5] Ayers DC, Athanasou NA, Woods CG, Duthie RB. Dialysis arthropathy of the hip. Clin Orthop 1993; 290: 216-24.

[6] Goldstein S, Winston E, Chung TJ, Chorpa S, Pariser K. Chronic arthropathy in long- term hemodialysis. Am J Med 1985; 78: 82-6.

[7] Fukunishi S, Yoh K, Kamae S, Yoshiya S. Beta 2-microglobulin amyloid deposit in HLA-B27 transgenic rats. Mod Rheumatol 2007; 17: 380-4.

[8] Crawford R, Athanasou NA. Beta 2-microglobulin amyloid deposition in hip revision arthroplasty tissues. Histopathology 1998; 33: 479-84.

[9] Lieberman JR, Fuchs MD, Hass SB, et al. Hip arthroplasty in patients with chronic renal failure. J Arthroplasty 1995; 10: 191-5.

[10] Radford PJ, Doran A, Greatorex RA, et al. Total hip replacement in the renal transplant recipient. J Bone Joint Surg 1989; 71B: 456-9.

[11] Gualtieri G, Vellani G, Dallari D, et al. Total hip arthroplasty in patients dialysis or with renal transplants. Chir Organi Mov 1995; 80: 139-45.

[12] Harris WH. Traumatic arthritis of the hip after dislocation and acetabular fractures: treatment by mold arthroplasty. An end-result study using a new method of result evaluation. J Bone Joint Surg 1969; 51A: 737-55.

[13] Gruen TA, McNeice GM, Amstutz H. "Modes of failure" of cemented stem-type femoral components: a radiographic analysis of loosening. Clin Orthop 1979; 121: 17-27.

[14] DeLee JG, Charnley J. Radiological demarcation of cemented sockets in total hip replacement. Clin Orthop 1976; 121: 20-32.

[15] Engh CA, Massin P, Suthers KE. Roentgenographic assessment of biologic fixation of porous-surfaced femoral components. Clin Orthop 1990; 257: 107-28.

[16] Harris WH, McCarthy Jr JC, OTNeill DA. Femoral component loosening using contemporary techniques of femoral cement fixation. J Bone Joint Surg 1982; 64A: 1063-7.

[17] Paparello J, Kshirsagar A, Batlle D. Comorbidity and cardiovascular risk factors in patients with chronic kidney disease. Semin Nephrol 2002; 22: 494-506.

[18] García-Ramiro S, Cofán F, Esteban PL, et al. Total hip arthroplasty in hemodialysis and renal transplant patients. Hip Int 2008r; 18(1): 51-7.

[19] Fukunishi S, Yoh K, Yoshiya S. Bone graft for large bone cysts of the femoral neck in patients on hemodialysis. Clin Orthop 2007; 461: 175-9. 
[20] Abbott KC, Bucci JR, Agodoa LY. Total hip arthroplasty in chronic dialysis patients in the United States. J Nephrol 2003; 16: 34-9.

[21] Lieberman JR, Fuchs MD, Haas SB, et al. Hip arthroplasty in patients with chronic renal failure. J Arthroplasty 1995; 10: 191-5.

[22] Bizot P, Witvoet J, Sedel L. Avascular necrosis of the femoral head after allogenic bone-marrow transplantation. A retrospective study of 27 consecutive THAs with a minimal two-year followup. J Bone Joint Surg 1996; 78B: 878-83.

[23] 23 Poggio D, García-Ramiro S, Rovira M, Combalía A, Gallart X, Riba J. Tratamiento quirúrgico de la necrosis isquémica de cabeza femoral después de un trasplante de progenitores hematopoyéticos. Med Clin (Barc) 2006; 127(19): 738-40.

[24] Noble JA, Caces MF, Steffens RA, Stinson FS. Cirrhosis hospitalization and mortality trends, 1970-87. Public Health Rep 1993; 108: 192-7.

[25] Singh GK, Hoyert DL. Social epidemiology of chronic liver disease and cirrhosis mortality in the United States, 1935-1997: trends and differentials by ethnicity, socioeconomic status, and alcohol consumption. Hum Biol 2000; 72: 801-20.

[26] Friedman LS. The risk of surgery in patients with liver disease. Hepatology 1999; 29: 1617-23.

[27] Ziser A, Plevak DJ, Wiesner RH, Rakela J, Offord KP, Brown DL. Morbidity and mortality in cirrhotic patients undergoing anesthesia and urgery. Anesthesiology 1999; 90: 42-53.

[28] Patel T. Surgery in the patient with liver disease. Mayo Clin Proc 1999; 74: 593-9.

[29] Mansour A, Watson W, Shayani V, Pickleman J. Abdominal operations in patients with cirrhosis: still a major surgical challenge. Surgery $1997 ; 122$ : 730-6.

[30] Aranha GV, Greenlee HB. Intra-abdominal surgery in patients with advanced cirrhosis. Arch Surg 1986; 121: 275-7.

[31] Child CG, Turcotte JG. Surgery and portal hypertension. Major Probl Clin Surg 1964; 1: 1-85.

[32] Shih LY, Cheng CY, Chang CH, Hsu KY, Hsu RW, Shih HN. Total knee arthroplasty in patients with liver cirrhosis. J Bone Joint Surg Am 2004; 86-A(2): 335-41.

[33] Borzio M, Salerno F, Piantoni L, et al. Bacterial infection in patients with advanced cirrhosis: a multicentre prospective study. Dig Liver Dis 2001; 33: 41-8.

[34] Navasa M, Fernandez J, Rodes J. Bacterial infections in liver cirrhosis. Ital J Gastroenterol Hepatol 1999; 31: 616-25.

[35] Deschenes M, Villeneuve JP. Risk factors for the development of bacterial infections in hospitalized patients with cirrhosis. Am J Gastroenterol 1999; 94: 2193-7.

[36] Bolognesi M, Merkel C, Bianco S, et al. Clinical significance of the evaluation of hepatic reticuloendothelial removal capacity in patients with cirrhosis. Hepatology 1994; 19: 628-34

[37] Fiuza C, Salcedo M, Clemente G, Tellado JM. In vivo neutrophil dysfunction in cirrhotic patients with advanced liver disease. J Infect Dis 2000; 182: 526-33.

[38] Guarner C, Runyon BA. Macrophage function in cirrhosis and the risk of bacterial infection. Hepatology 1995; 22: 367-9.

[39] Amitrano L, Guardascione MA, Brancaccio V, Balzano A. Coagulation disorders in liver disease. Semin Liver Dis 2002; 22: 83-96.

[40] Task Force on Blood Component Therapy. Practice guidelines for blood component therapy. A report by the American Society of Anesthesiologists Task Force on Blood Component Therapy. Anesthesiology 1996; 84: 732-47.

[41] Lamas JL, Ocampo A, Martínez-Vázquez C, et al. Asymptomatic osteonecrosis of the hip in HIV-infected patients. Enferm Infecc Microbiol Clin 2010; 28: 150-5.

[42] Monier P, McKown K, Bronze MS. Osteonecrosis complicating highly active antiretroviral therapy in patients infected with human immunodeficiency virus. Clin Infect Dis 2000; 31: 1488-92.

[43] Glesby MJ. Bone disorders in human immunodeficiency virus infection. Clin Infect Dis 2003; 37(Suppl 2): S91-5.

[44] Calza L, Manfredi R, Chiodo F Osteonecrosis in HIV-infected patients and its correlation with highly active antiretroviral therapy (HAART). Presse Med 2003 5; 32: 595-8.

[45] Powell DL, Whitener CJ, Dye CE, Ballard JO, Shaffer ML, Eyster ME. Knee and hip arthroplasty infection rates in persons with haemophilia: a 27 year single center experience during the HIV epidemic. Haemophilia 2005; 11: 233-9.
[46] Parvizi J, Sullivan TA, Pagnano MW, Trousdale RT, Bolander ME. Total joint arthroplasty in human immunodeficiency virus-positive patients: an alarming rate of early failure. J Arthroplasty 2003; 18: 259-64.

[47] Harrison WJ. HIV/AIDS in trauma and orthopaedic surgery. J Bone Joint Surg Br 2005; 87: 1178-81.

[48] Wroblewski BM, Siney PD, Fleming PA. Charnley low-frictional torque arthroplasty for avascular necrosis of the femoral. J Arthroplasty 2005; 20: 870-3.

[49] Bizot P, Nizard R, Socie G, Gluckman E, Witvoet J, Sedet L. Femoral head osteonecrosis after bone marrow transplantation. Clin Orthop 1998; 357: 127-34.

[50] Dudkiewicz I, Covo A, Salai M, Israeli A, Amit Y, Chechik A Total hip arthroplasty alter avascular necrosis of the femoral head: does etiology affect the results? Arch Orthop Trauma Surg 2004 24: 82-5.

[51] Winkler H. Rationale for one stage exchange of infected hip replacement using uncemented implants and antibiotic impregnated bone graft. Int J Med Sci 2009; 6: 247-52.

[52] Poggio D, García S, Rovira M, Combalía A, Gallart X, Riba J. Surgical treatment for vascular necrosis of femoral head after hematopoietic stem cell transplantation. Med Clin (Barc) 2006 18; 127: 738-40

[53] Tornero E, García S, Larrousse M, et al. Total hip arthroplasty in HIV-infected patients: a retrospective, controlled study. HIV Med 2012; 13(10): 623-9.

[54] Soriano A, Popescu D, García S, et al. Usefulness of teicoplanin for preventing methicillin-resistant Staphylococcus aureus infections in orthopedic surgery. Eur J Clin Microbiol Infect Dis 2006; 25(1): 35-8

[55] Ridgeway S, Wilson J, Charlet A. Infection of the surgical site alter arthroplasty of the hip. J Bone Joint Surg Br 2005; 87: 844-50.

[56] Mini E, Nobili S, Periti P. Methicillin-resistant staphylococci in clean surgery. Is there a role for prophylaxis? Drugs 1997; 54 (Suppl 6): 39-52

[57] Kalmeijer MD, Nieuwland-Bollen E, Bogaers-Hofman D, de Baere GA. Nasal carriage of Staphylococcus aureus is a major risk factor for surgical-site infections in orthopedic surgery. Infect Control Hosp Epidemiol 2000; 21: 319-23.

[58] Kalmeijer MD, Coertjens H, Nieuwland-Bollen PM. Surgical site infections in orthopedic surgery: the effect of mupirocin nasal ointment in a double-blind, randomized, placebo-controlled study. Clin Infect Dis 2002; 346: 1871-7.

[59] Perl TM, Cullen JJ, Wenzel RP. Intranasal mupirocin to prevent postoperative Staphylococcus aureus infections. N Eng J Med 2002; 346: 1871-7.

[60] Bode LG, Kluytmans JA, Wertheim HF. Preventing surgical-site infections in nasal carriers of Staphylococcus aureus. N Eng J Med 2010; 362: 9-17

[61] Darouiche RO, Hamill RJ, Musher DM, Young EJ, Harris RL. Periprosthetic candidal infections following arthroplasty. Rev Infect Dis 1989; 11: 89-96.

[62] Azzam K, Parvici J, Jungkind D, et al. Microbiological, clinical and surgical features of fungal prosthetic joint infections: a multiinstitutional experience. J Bone Joint Surg 2009; 91(Suppl 6): 1429.

[63] Phelan DM, Osmon DR, Keating MR, Hansen AD. Delayed reimplantation arthroplasty for candidal prosthetic joint infection: a report of 4 cases and review of the literature. Clin Infect Dis 2002; 34: $930-8$

[64] Lazzarini L, Manfrin V, De Lalla F. Candidal prosthetic hip infection in a patient with candidal previous septic arthritis. J Arthroplasty 2004; 19: 248-52.

[65] Simonian PT, Brause BD, Wickiewicz TL. Candida infection after total knee arthroplasty. Management without resection or amphotericin B. J Arthroplasty 1997; 12: 825-9.

[66] Ramamohan N, Zeineh N, Grigoris P, Butcher I. Candida glabrata infection after total hip arthroplasty. J Infect 2001; 42: 74-6.

[67] Moises J, Calls J, Ara J, et al. Candida parapsilosis sepsis in a patient on mantenaince haemodialysis with a hip joint replacement. Nefrología 1998; 18: 330-32.

[68] Merrer J, Dupont B, Nieszkowska A, De Jonghe B, Outin H. Candida albicans prosthetic arthritis treated with fluconazol alone. J Infect 2001; 42: 208-9. 
[69] Yang SH, Pao JL, Hang YS. Staged reimplantation of total knee arthroplasty after Candida infection. J Arthroplasty 2001; 1: 52932.

[70] Kawanabe K, Hayashi H, Miyamoto M, Tamura J, Shimizu M, Nakamura T. Candida septic arthritis of the hip in a young patient without predisposing factors. J Bone Joint Surg Br 2003; 85: 734-5.

[71] Younkin S, Evarts CM, Steigbigel RT. Candida parapsilosis infection of a total hip joint replacement: successful reimplantation after treatment with amphotericin B and 5-fluorocytosine. A case report. J Bone Joint Surg Am 1984; 66: 142-3.

[72] Goodman JS, Seibert DG, Reahl GE Jr, Geckler RW. Fungal infection of prosthetic joints: a report of two cases. J Rheumatol 1983; 10: 494-5.

[73] Wada M, Baba H, Imura S. Prosthetic knee Candida parapsilosis infection. J Arthroplasty 1998; 13: 479-82.

[74] García-Oltra E, García-Ramiro S, Martínez JC, et al. Prosthetic joint infection by Candida spp. Rev Esp Quimioter 2011; 24(1): 3741
[75] Vilchez F, Martinez-Pastor JC, García-Ramiro S, et al. Outcome and predictors of treatment failure in early post-surgical prosthetic joint infections due to Staphilococcus aureurs treated with debridement. Clin Microbiol Infect 2011; 17(3): 439-44.

[76] Melo AS, Bizerra FC, Freymüller E, Arthington-Skaggs BA, Colombo AL. Biofilm production and evaluation of antifungal susceptibility amongst clinical Candida spp. Isolates, including strains of the Candida parapsilosis complex. Med Mycol 2010 (En prensa).

[77] Kucharíková S, Tournu H, Holtappels M, Van Dijck P, Lagrou K. In vivo efficacy of anidulafungin against mature Candida albicans biofilms in a novel rat model of catheter-associated Candidiasis Antimicrob Agents Chemother 2010; 54: 4474-5.

[78] Tobudic S, Kratzer C, Lassnigg A, Graninger W, Presterl E. In vitro activity of antifungal combinations against Candida albicans biofilms. J Antimicrob Chemother 2010; 65: 271-4.

(C) Tornero et al.; Licensee Bentham Open.

This is an open access article licensed under the terms of the Creative Commons Attribution Non-Commercial License (http://creativecommons.org/licenses/by-nc/3.0/) which permits unrestricted, non-commercial use, distribution and reproduction in any medium, provided the work is properly cited. 